\title{
Growing evidence for a weighty problem
}

\author{
Ernest G. Chan, BS, and Jonathan D'Cunha, MD, PhD
}

See related article on pages 1185-91.

In 1994, work evaluating the effects of the positional cloning of the murine obese gene was especially striking. ${ }^{1}$ Mutation of the gene in mice resulted in profound obesity and type 2 diabetes as part of a syndrome that resembled morbid obesity in human beings (Figure 1). Not surprisingly, murine models of obesity have been used subsequently to help parse the relationship between human obesity and several human diseases. Cancer is no exception.

There is unquestionable evidence in support of a dramatic relationship between obesity and cancer. In the United States alone, the amount of obese or overweight individuals has reached $65 \%$ of the population. ${ }^{2}$ With the prevalence of obesity at epidemic levels, the relationship between cancer and obesity has many implications worldwide. Historically, the relationship between obesity and cancers such as those of the breast, colon, liver, and more have been well documented..$^{3-7}$ The rise in the incidence of esophageal cancer mirrors the increase in obesity in the population. How these epidemiologic observations are linked at the molecular level remains unclear and complex. The article in this issue of the Journal of Thoracic and Cardiovascular Surgery by Fowler and colleagues ${ }^{8}$ attempts to examine the relationship between obesity and EAC further. The importance in identifying the connection between increased weight and EAC cannot be stressed enough, especially with the $300 \%$ increase in EAC incidence rate over the past 25 years. ${ }^{9}$

A strong linear relationship between EAC and increased body mass index, a measurement of obesity, has been identified in the literature. A recent systematic review and meta-analysis of more than 140 studies showed a strong association between a 5-unit increase in body mass index and EAC in both men and women. ${ }^{10}$ However, until this study by Fowler and colleagues, the use of actual biomarkers and bioactive molecules to confirm the connection has been rarely thrown into the spotlight. Heightened body weight,

From the Department of Cardiothoracic Surgery, University of Pittsburgh Medical Center, Pittsburgh, Pa.

Disclosures: Authors have nothing to disclose with regard to commercial support.

Received for publication Jan 20, 2015; accepted for publication Jan 21, 2015; available ahead of print March 3, 2015.

Address for reprints: Jonathan D'Cunha, MD, PhD, Department of Cardiothoracic Surgery, University of Pittsburgh Medical Center, UPMC Presbyterian, Suite C-900, 200 Lothrop St, Pittsburgh, PA 15213 (E-mail: dcunhaj@upmc.edu).

J Thorac Cardiovasc Surg 2015;149:1192-3

$0022-5223 / \$ 36.00$

Copyright (c) 2015 by The American Association for Thoracic Surgery

http://dx.doi.org/10.1016/j.jtcvs.2015.01.041 abdominal circumference, and anthropomorphic measurements have been highly associated with gastroesophageal reflux disease (GERD), 1 of the major risk factors of EAC. The association between GERD and increased body mass index is well documented. Pathophysiologically, overweight and obese individuals have a significantly higher rate of transient lower esophageal sphincter relaxation (TLOSR) than patients in a normal weight group in a study done to look at the association between postprandial TLOSR and anthropomorphic measurements. This increase in TLOSR rate may be a key factor in the initiating event in the pathogenesis of GERD that leads to Barrett's esophagus and EAC. ${ }^{11}$

Fowler and colleagues take a different approach to identifying the correlation between heightened body weight and EAC. Instead of just examining physical measurements, such as body part to body part ratios and body mass index, they look at the esophageal cancer development in an immunocompromised murine xenograft model to elucidate some of the molecular details in the process of esophageal cancer growth. The finesse in the design lies in taking advantage of many well-known bioactive molecules with inflammatory and protumorigenic properties to ultimately confirm the molecular contribution of obesity to the pathogenesis of EAC. Using a high-fat diet to induce obesity, the investigators looked at leptin because of its known link to increased risk of Barrett's esophagus and increased proliferation in vitro. They also evaluated adiponectin, a protein that induces apoptosis of an EAC cell line in vitro. ${ }^{12,13}$ Their results confirm well-studied correlations. They were ultimately able to also identify an upregulation of several other adipokines with inflammatory and protumorigenic properties such as insulin-like growth factor-binding protein and fibroblast growth factor- $\alpha$ as well as a decrease in expression of protective markers such as cluster of differentiation 26, lipocalin, and retinol binding protein 4 . Tumors in the high-fat-diet mice displayed increased growth and were found to be $53 \%$ larger after 4 weeks. To measure tumors in vivo, they simulated positron emission tomography scans using labeled 2-deoxyglucose and measured uptake with an infrared probe. Their findings in vivo paralleled the direct tumor measurements.

All of these findings definitely help point investigators in the right direction to identifying how obesity contributes to the development of EAC. However, the findings of these studies are in the context of only 1 specific EAC cell line (ie, OE33). Given the complexity and time commitment of this type of study, it is understandable that the data 


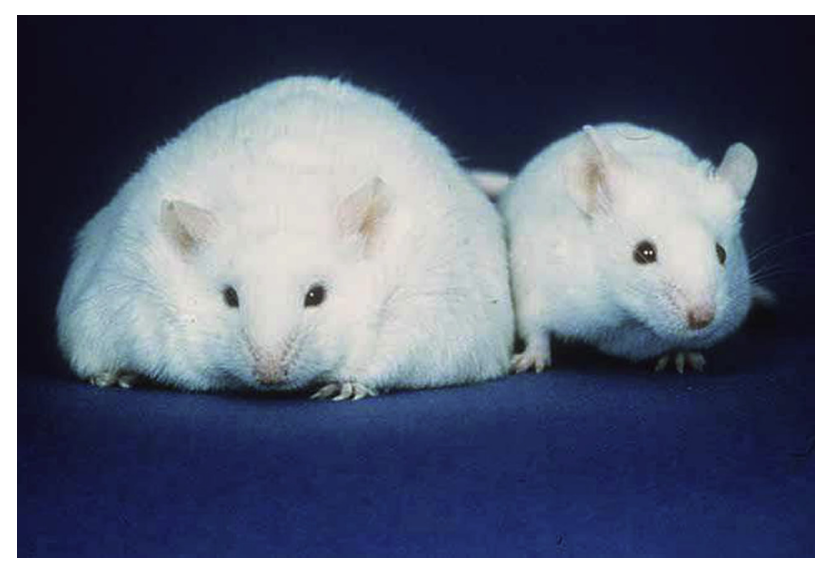

FIGURE 1. Obese and normal-weight mice.

were presented in this context; however, this underscores the importance of study design and model development from the outset. The difference in tumor measurements also barely achieved statistical significance because OE33 tumors displayed increased growth in the mice fed the high-fat diet $(P=.046)$. Similar results with the use of multiple xenografts would provide readers with more confidence of the generalizability of the observations. Do the above statements about leptin and adiponectin apply to only the OE33 EAC cell line? Are the observations really valid and would a larger experimental number give us greater confidence in the findings? We will not have a definitive answer to this question until other cell lines or models like the Barrett's esophagus to EAC transgenic murine model are studied. Moreover, their method of induction of EAC in the mice precludes the study's ability to identify whether markers associated with obesity have a causative relationship with EAC. Although this may not fall within the scope of the study, this knowledge may be more useful for the development of preventative measures. The study would also be strengthened by in-depth evaluation of the tumors and their malignant potential beyond the relatively high-level biological readouts presented.

\section{CONCLUSIONS}

The authors conclude their study with identifying their article as the "first steps toward developing improved treatment for patients with EAC," and they could not have made a truer statement. ${ }^{8}$ Although they were unable to identify a causative relationship or provide any information regarding other esophageal cancer cell lines and the inherent tumorigenic properties of the stimulated xenografts, their study provides a glimpse into the nature of how obesity may increase the risk of esophageal cancer growth. With this knowledge, we can look at the next steps in greater detail, both with tumorigenesis and molecular mechanisms, such that a deeper understanding of the link between obesity and EAC are elucidated.

\section{References}

1. Zhang Y, Proenca R, Maffei M, Barone M, Leopold L, Friedman JM. Positional cloning of the mouse obese gene and its human homologue. Nature. 1994;372: 425-32.

2. Flegal KM, Carroll MD, Ogden CL, Johnson CL. Prevalence and trends in obesity among US adults, 1999-2000. JAMA. 2002;288:1723-7.

3. Simard EP, Ward EM, Siegel R, Jemal A. Cancers with increasing incidence trends in the United States: 1999 through 2008. CA Cancer J Clin. 2012;62: 118-28.

4. Edelstein ZR, Farrow DC, Bronner MP, Rosen SN, Vaughan TL. Central adiposity and risk of Barrett's esophagus. Gastroenterology. 2007;133: 403-11.

5. Nair S, Nguyen H, Salama S, Al-Hendy A. Obesity and the endometrium: adipocyte-secreted proinflammatory TNF alpha cytokine enhances the proliferation of human endometrial glandular cells. Obstet Gynecol Int. 2013;2013: 368543.

6. Sundaram S, Freemerman AJ, Johnson AR, Milner JJ, McNaughton KK, Galanko JA, et al. Role of HGF in obesity-associated tumorigenesis: C3(1)TAg mice as a model for human basal-like breast cancer. Breast Cancer Res Treat. 2013;142:489-503.

7. Olivo-Marston SE, Hursting SD, Perkins SN, Schetter A, Khan M, Croce C, et al. Effects of calorie restriction and diet-induced obesity on murine colon carcinogenesis, growth and inflammatory factors, and microRNA expression. PLoS One. 2014;9:e94765.

8. Fowler AJ, Richer AL, Bremner RM, Inge LJ. A high-fat diet is associated with altered adipokine production and a more aggressive esophageal adenocarcinoma phenotype in vivo. J Thorac Cardiovasc Surg. 2015;149:1185-91.

9. Brown LM, Devesa SS, Chow WH. Incidence of adenocarcinoma of the esophagus among white Americans by sex, stage, and age. J Natl Cancer Inst. 2008; 100:1184-7.

10. Renehan AG, Tyson M, Egger M, Heller RF, Zwahlen M. Body-mass index and incidence of cancer: a systematic review and meta-analysis of prospective observational studies. Lancet. 2008;371:569-78.

11. Wu JC, Mui LM, Cheung CM, Chan Y, Sung JJ. Obesity is associated with increased transient lower esophageal sphincter relaxation. Gastroenterology. 2007;132:883-9.

12. Ogunwobi O, Mutungi G, Beales IL. Leptin stimulates proliferation and inhibits apoptosis in Barrett's esophageal adenocarcinoma cells by cyclooxygenase-2dependent, prostaglandin-E2-mediated transactivation of the epidermal growth factor receptor and c-Jun NH2-terminal kinase activation. Endocrinology. 2006; $147: 4505-16$

13. Somasundar P, Riggs D, Jackson B, Vona-Davis L, McFadden DW. Leptin stimulates esophageal adenocarcinoma growth by nonapoptotic mechanisms. Am J Surg. 2003;186:575-8. 